Article

\title{
Grinding Optimization of Cassiterite-Polymetallic Sulfide Ore
}

\author{
Jinlin Yang ${ }^{1,2}$, Zhichao Shuai ${ }^{1}$, Wentao Zhou ${ }^{1,3}$ and Shaojian Ma ${ }^{1,2, *}$ \\ 1 College of Resources, Environment and Materials, Guangxi University, Nanning 530004, China; \\ jlyang523@126.com (J.Y.); zhanghm420@126.com (Z.S.); zhou13840541273@163.com (W.Z.) \\ 2 Guangxi Key Laboratory of Processing for Nonferrous Metallic and Featured Materials, Guangxi University, \\ Nanning 530004, China \\ 3 College of Resources and Civil Engineering, Northeastern University, Shenyang 110819, China \\ * Correspondence: jlyang523@126.com; Tel.: +86-0771-3232200
}

Received: 27 November 2018; Accepted: 3 February 2019; Published: 25 February 2019

check for updates

\begin{abstract}
Due to the differences in beneficiation methods and mineral properties between cassiterite ore and polymetallic sulfide ore, there is an inherent contradiction between cassiterite overgrinding and sulfide ore undergrinding. A method to optimize and characterize the grinding performance is presented in this paper. In this method, the grinding characteristics are defined by the qualified particle size range index under unit energy consumption. By changing the grinding time, grinding concentration, and filling ratio, the optimized grinding conditions were evaluated, and they were predicted and verified by the response surface method. The results corroborate that when the grinding time of cassiterite is $4 \mathrm{~min}$ and the grinding time of sulfide ore is $8 \mathrm{~min}$, the grinding qualified size range index under unit energy consumption is the largest. Cassiterite is brittle and easy to grind due to low hardness, while sulfide is difficult to grind due to high hardness. Hence, the time to beneficiate tin ore is when the grinding time is $4 \mathrm{~min}$, and that to beneficiate sulfide ore is when the regrinding time is approximately $4 \mathrm{~min}$. In this way, the contradiction between overgrinding cassiterite and undergrinding sulfide ore can be alleviated on the basis of the most effective utilization of grinding energy. The optimal grinding concentration and filling ratio are $65 \%$ and $37 \%$, respectively. The response surface prediction and test results are almost identical, with an error of $\pm 2 \%$. Thus, the effectiveness of grinding characterization method is verified.
\end{abstract}

Keywords: cassiterite polymetallic sulfide ore; undergrinding; overgrinding; characterization; grinding optimization

\section{Introduction}

The Dachang ore field in Guangxi China is an important resource base with tin, lead, antimony, zinc. The main resource is cassiterite polymetallic sulfide ore. The primary useful minerals of cassiterite polymetallic sulfide ore are cassiterite, pyrite, pyrrhotite, arsenopyrite, sphalerite, jamesonite, and small amounts of sphalerite, tetrahedrite tin, galena, and chalcopyrite. Gangue minerals are mainly quartz and calcite [1]. This type of tin ore must be comprehensively utilized because of its many associated mineral components and complex occurrence of elements. A tin concentrator should consider not only the enrichment and separation of main minerals, but also the comprehensive recovery of minor minerals and dispersed elements. There are many mineral products and many ore dressing methods, and the ore dressing process is complex. Therefore, it is difficult to regulate and manage the production of a tin concentrator for this type of ore, among which the adjustment and control of grinding operation are the most complex [2]. 
It is well known that the particle size characteristics of grinding products have a significant impact on the efficiency of subsequent separation operations. Optimal operation of grinding and particle size control of grinding products are key technologies that need to be solved urgently in the field of mineral processing and powder engineering. However, for different ores, the importance and difficulty of grinding optimization operation and grinding product size control are different. Production practice shows that the most important but also the most difficult problems for tin concentrators dealing with cassiterite polymetallic sulphide ores are the optimal operation of grinding operations and the particle size control of grinding products. The reasons are as follows: (1) cassiterite and sulfide minerals have great differences in physical and mechanical properties, and selective fragmentation is obvious. Compared with sulphide minerals, cassiterite is brittle and fragile, with high density and is easy to settle and enrich in grinders and classifications. Therefore, cassiterite is often preferentially broken and repeatedly broken in grinders, which makes cassiterite easy to enrich in fine grains of grinding products and increases the difficulty of recovery. (2) Different processing methods exist between cassiterite and sulfide minerals. The required grinding size is also different. Sulfide minerals are usually enriched and separated from each other by flotation. They are suitable for feeding materials ranging approximately $-0.15+0.010 \mathrm{~mm}$, so the ore needs to be finely ground. The main method of enriching and recovering cassiterite is gravity separation, and the optimal particle size range is approximately $-0.25+0.075 \mathrm{~mm}$, hence requiring coarsely ground ore [3-8]. It is difficult to satisfy both the requirements of rough grinding of cassiterite and fine grinding of sulfide, and this finally results in a large amount of cassiterite that is ground to a fine level, with a high loss rate of tin tailings that is difficult to recover.

It is not adequate to make the grinding particle size coarse so as to reduce the generation of fine cassiterite, which will lead to inadequate dissociation of sulfide ore; moreover, the quality of the flotation concentrate is poor, and the metal mutual loss is serious [3]. Therefore, there is an inherent contradiction between cassiterite overgrinding and sulfide ore undergrinding, which leads to low-grade sulfide concentrate, a serious loss of cassiterite and a waste of mineral resources. In order to tackle this issue, many studies have been conducted on the optimization of grinding media, grinding circuits and grinding models [9-13]. However, there is little research on the optimization method of grinding process. Thus, research on a characterization method for grinding process control of the cassiterite polymetallic sulfide ore grinding effect is urgently needed.

Through grinding optimization, target particle size and the dissociation of useful minerals can be judged. Therefore, under the premise of achieving the target size and high grinding energy efficiency, the innovation of this paper is to make the distribution of useful mineral metals accumulate as much as possible in the target particle size range. Therefore, this paper proposes a grinding optimization characterization method, namely, the unit-energy consumption of metal-grade accumulation of qualified particle size, to characterize the grinding characteristics of the required particle size. The optimum conditions of cassiterite polymetallic sulfide ore were studied. In addition, the response surface method was used to predict and verify the optimization conditions by changing the three grinding operation factors, i.e., the grinding time, grinding concentration, and filling ratio.

\section{Materials, Equipment and Methods}

\subsection{Materials and Equipment}

Experimental materials of cassiterite polymetallic sulfide ore were obtained from the Dachang ore field in Guangxi, China. The main useful minerals of cassiterite polymetallic sulfide ore were marmatite, cassiterite, pyrite, pyrrhotite, jamesonite, arsenopyrite, and marcasite. The main gangue minerals were quartz and calcite. All samples were broken into $-1.7 \mathrm{~mm}$ particles after cleaning, drying, crushing, mixing and reduction processes. The test equipment mainly included a laboratory jaw crusher, conical ball mill, Bond power index ball mill, vibration screen and oven. 


\subsection{Methods}

Grinding is the process of first grinding a material into a particle size (such as $a$ ) and then specifying a particle size (such as $b$ ) that was over-grinded. Accordingly, the particle size between $a$ and $b$ was the required particle size. The grinding technical efficiency can be used to evaluate the efficiency of the required granularity [1]. The grinding technical efficiency is defined as the grinding efficiency of particle size $a$ minus the grinding efficiency of particle size $b$, with the mathematical expression of grinding efficiency shown in Equation (1).

$$
E=\left(\frac{\gamma-\gamma_{1}}{100-\gamma_{1}}-\frac{\gamma_{3}-\gamma_{2}}{100-\gamma_{2}}\right)
$$

where $E$ represents the grinding technical efficiency $(\%) ; \gamma$ represents the yield of the grinding product, which is less than particle size $a(\%) ; \gamma_{1}$ represents the yield of the grinding feed, which is less than particle size $a(\%) ; \gamma_{2}$ represents the yield of the grinding feed, which less than particle size $b, \%$; and $\gamma_{3}$ represents the yield of the grinding product, which is less than particle size $b(\%)$. The higher the grinding efficiency, the higher the particle size requirements, and the better the grinding effect produced.

Grinding technical efficiency can be used to characterize the cumulative effect of the qualified particle size. Moreover, the metal distribution rate can characterize the metal grade ratio of the qualified particle size. These two products can represent the cumulative effect of the metal grade on the qualified particle size. The larger the product, the greater the metal grade accumulation in the qualified particle size, and the better the grinding effect produced. The two relations are shown in Equation (2).

$$
W=E \cdot D
$$

Here, $W$ can be expressed as a mathematical quantity related to the accumulation of the qualified particle size metal grade. The concept of the qualified particle size index of the grinding can be used to characterize it $(\%)^{2}$, and $D$ is the metal distribution rate $(\%)$.

As mentioned in the previous article, different minerals have different particle sizes suitable for separation, and the separation method is also inconsistent. Sulfide minerals are usually enriched and separated from each other by flotation, and the optimal feeding particle size range is approximately -0.15 $+0.010 \mathrm{~mm}$. The main method of enriching and recovering cassiterite is gravity separation, and the optimal feeding particle size range is approximately $-0.25+0.075 \mathrm{~mm}$. To fulfill the requirements of the actual concentrator and provide more precise test data, $-0.23+0.075 \mathrm{~mm}$ was chosen as the requirement grade for cassiterite in cassiterite-polymetallic sulfide ore, i.e., the grinding particle size $a$ of cassiterite was $0.23 \mathrm{~mm}$ and the grinding particle size $b$ was $0.075 \mathrm{~mm}$. In addition, $-0.15+0.038 \mathrm{~mm}$ was chosen as the requirement grade for sulfide ore in cassiterite-polymetallic sulfide ore, with grinding particle size $a$ of sulfide ore at $0.23 \mathrm{~mm}$ and grinding particle size $b$ at $0.075 \mathrm{~mm}$.

An example can be given to illustrate the calculation process when the grinding time is $2 \mathrm{~min}$, as shown Tables 1 and 2.

\begin{tabular}{|c|c|c|c|c|c|}
\hline \multirow{2}{*}{$\begin{array}{l}\text { Particle } \\
\text { Size/mm }\end{array}$} & \multirow{2}{*}{$\begin{array}{l}\text { Undersize Yield } \\
(\gamma) /(0 \mathrm{~min}) \%\end{array}$} & \multirow{2}{*}{$\begin{array}{l}\text { Undersize Yield } \\
(\gamma) /(2 \mathrm{~min}) \%\end{array}$} & \multicolumn{3}{|c|}{ Metal Distribution Rate $(D) /(2 \mathrm{~min}) \%$} \\
\hline & & & $D(\mathrm{Sn})$ & $D(\mathrm{Zn})$ & $D(\mathrm{~Pb})$ \\
\hline$-1.7+1$ & 100.00 & 100.00 & 3.79 & 11.20 & 14.46 \\
\hline$-1+0.425$ & 82.55 & 97.30 & 31.75 & 10.30 & 8.43 \\
\hline$-0.425+0.23$ & 52.16 & 95.77 & 14.69 & 13.75 & 6.93 \\
\hline$-0.23+0.15$ & 36.94 & 93.76 & 7.58 & 16.15 & 13.25 \\
\hline$-0.15+0.075$ & 16.11 & 84.57 & 13.27 & 16.86 & 14.16 \\
\hline$-0.075+0.038$ & 10.66 & 72.07 & 15.40 & 16.75 & 15.06 \\
\hline-0.038 & 4.56 & 29.65 & 13.51 & 14.98 & 27.71 \\
\hline
\end{tabular}

Table 1. Undersize yield and metal distribution rate with a grinding time of 2 Min. 
Table 2. The Qualified Particle Size Index $(W)$ with Grinding Time of 2 min.

\begin{tabular}{ccccccccc}
\hline Mineral/Element & $\begin{array}{c}\text { Optimal } \\
\text { Feeding Particle } \\
\text { Size/mm }\end{array}$ & $\gamma / \%$ & $\gamma_{\mathbf{1}} / \%$ & $\gamma_{2} / \%$ & $\gamma_{\mathbf{3}} / \%$ & $\mathbf{E} / \%$ & $\begin{array}{c}\text { Metal } \\
\text { Distribution } \\
\text { Rate }(\boldsymbol{D}) / \%\end{array}$ & $\begin{array}{c}\text { Qualified } \\
\text { Particle Size } \\
\text { Index }(\boldsymbol{W}) /(\%)^{2}\end{array}$ \\
\hline Cassiterite/(Sn) & $-0.23+0.075$ & 93.76 & 36.94 & 10.66 & 72.07 & 1.59 & 20.85 & 33.12 \\
Sulfide/(Zn) & $-0.15+0.038$ & 84.57 & 16.11 & 4.56 & 29.65 & 1.08 & 33.61 & 36.26 \\
Sulfide/(Pb) & $-0.15+0.038$ & 84.57 & 16.11 & 4.56 & 29.65 & 1.08 & 29.22 & 31.53 \\
\hline
\end{tabular}

For calculating the cumulative effect of the metal grade on the qualified particle size of cassiterite and sulfide ore, the first step is to calculate the yield of each particle size by grinding and sieving. The second step is to confirm the target particle size of grinding technology efficiency. The target grade of cassiterite is $-0.23 \mathrm{~mm}+0.075 \mathrm{~mm}$ and that of sulfide ore is $-0.15+0.038 \mathrm{~mm}$, and the grinding technology efficiency is calculated by Equation (1). The third step is to confirm the metal distribution rate and analyze the metal distribution rate of the target particle size through laboratory analysis. The fourth step is to calculate the metal accumulation in qualified particle size. The metal accumulation in each particle size can be obtained by multiplying the grinding technical efficiency and the metal distribution rate by Equation (2), which is the $W$ value.

Based on the concept of qualified grinding particle size index, the Equation of grinding energy consumption is put forward. The relation between grinding characteristic formula and the grinding energy consumption of the ball mill is discussed and the ratio between the grinding qualified particle size index and the energy consumption of grinding is compared. The ratio is signified by symbolic $M$, as shown in Equation (3) to represent the optimization effect of grinding; the $M$ value can be called grinding optimization degree.

$$
M=\frac{W}{W_{C}}
$$

The energy consumption of grinding can be solved by the Bond work index, and its expression is shown as follows:

$$
W_{C}=\frac{10 W_{I B}}{\sqrt{P}}-\frac{10 W_{I B}}{\sqrt{F}}
$$

where $W_{C}$ is the work consumed by crushing materials, $\mathrm{kw} \cdot \mathrm{h}$; and $W_{I B}$ is the work index, $\mathrm{kw} \cdot \mathrm{h} \cdot \mathrm{t}^{-1}$. $P$ and $F$ respectively represent $80 \%$ generation particle size and the ore feeding particle size through the mesh size $(\mu \mathrm{m})$.

As for how to determine the ball work index, the Bond ball work index formula uses a $305 \mathrm{~mm} \times$ $305 \mathrm{~mm}$ ball mill, as shown in Equation (5).

$$
W_{I B}=\frac{4.904}{P_{i}^{0.23} \cdot G_{r p}^{0.82} \cdot\left(P^{-0.5}-F^{-0.5}\right)}
$$

Here, $W_{I B}$ is the work index, $\mathrm{kw} \cdot \mathrm{h} \cdot \mathrm{t}^{-1}$; and $P_{i}$ is the sieve size of the test $(\mu \mathrm{m})$. The ball mill produces a new material smaller than $P_{i}$ per lap, $\mathrm{g} \cdot \mathrm{R}^{-1} . P$ and $F$ respectively represent $80 \%$ generation particle size and the ore feeding particle size through the mesh size $(\mu \mathrm{m})$.

The grinding energy consumption under each grinding condition can be calculated by Equation (4) and Equation (5) as shown in Table 3. $W_{I B}$ can be calculated by the Bond ball mill test [14]. $P$ and $F$ can be calculated by the undersized yield in grinding tests.

Table 3. The grinding optimization degree $(M)$ with a grinding time of $2 \mathrm{~min}$.

\begin{tabular}{cccccccc}
\hline Mineral/Element & $\begin{array}{c}\text { Optimal Feeding } \\
\text { Particle Size/mm }\end{array}$ & $\begin{array}{c}\text { Qualified Particle } \\
\text { Size Index }(\boldsymbol{W}) /(\%)^{\mathbf{2}}\end{array}$ & $\boldsymbol{F / \mu \mathrm { m }}$ & $\boldsymbol{P} / \boldsymbol{\mu m}$ & $\boldsymbol{W}_{\mathbf{I B}} / \mathbf{k w} \cdot \mathbf{h} \cdot \mathbf{t}^{-\mathbf{1}}$ & $\boldsymbol{W}_{\mathbf{C}} / \mathbf{k w} \cdot \mathbf{h}$ & $\begin{array}{c}\text { Grinding Optimization } \\
\mathbf{D e g r e e}(\boldsymbol{M})\end{array}$ \\
\hline Cassiterite/(Sn) & $-0.23+0.075$ & 33.12 & 614 & 100 & 15.10 & 9.01 & 3.67 \\
Sulfide/(Zn) & $-0.15+0.038$ & 36.26 & 614 & 100 & 15.10 & 9.01 & 4.02 \\
Sulfide/(Pb) & $-0.15+0.038$ & 31.53 & 614 & 100 & 15.10 & 9.01 & 3.50 \\
\hline
\end{tabular}




\section{Grinding Tests}

The bond ball mill work index test for the cassiterite polymetallic-sulfide ore milling bond work index is $W_{I B}=15.10$. The grinding energy consumption can be obtained under the condition of arbitrary grinding.

\subsection{Effect of Grinding Time}

The grinding test conditions were listed as follows: grinding time was set at $2 \mathrm{~min}, 4 \mathrm{~min}, 6 \mathrm{~min}$, $8 \mathrm{~min}$ and $10 \mathrm{~min}$; the grinding concentration at $65 \%$; the filling ratio at $32 \%$; the grinding particle size at $-1.7 \mathrm{~mm}$ and the rotational speed ratio at $80 \%$. The effect of grinding time on grinding optimization degree of the cassiterite sulfide ore is shown in Tables 4-6, and Figures 1 and 2. Sn is the metal element in the mineral cassiterite, $\mathrm{Pb}$ and $\mathrm{Zn}$ are the metal elements in sulfide minerals.

Table 4. Effect of grinding time on the $M(\mathrm{Sn})$.

\begin{tabular}{cccc}
\hline Grinding Time/min. & $\boldsymbol{W ( S n ) / ( \% ) ^ { \mathbf { 2 } }}$ & $\boldsymbol{W}_{\mathbf{C}} / \mathbf{k w} \cdot \mathbf{h} \cdot \mathbf{t}^{-\mathbf{1}}$ & $\mathbf{M ( S n )}$ \\
\hline 2 & 33.12 & 9.01 & 3.67 \\
4 & 72.26 & 13.51 & 5.35 \\
6 & 63.36 & 14.32 & 4.43 \\
8 & 79.91 & 15.06 & 5.31 \\
10 & 60.89 & 16.78 & 4.16 \\
\hline
\end{tabular}

Table 5. Effect of Grinding Time on the $M(\mathrm{Zn})$.

\begin{tabular}{cccc}
\hline Grinding Time/min & $\boldsymbol{W ( Z n ) / ( \% ) ^ { \mathbf { 2 } }}$ & $\mathbf{W}_{\mathbf{C}} / \mathbf{k w} \cdot \mathbf{h} \cdot \mathbf{t}^{-\mathbf{1}}$ & $\mathbf{M ( Z n )}$ \\
\hline 2 & 36.26 & 9.01 & 4.02 \\
4 & 61.58 & 13.51 & 4.56 \\
6 & 58.83 & 14.32 & 4.11 \\
8 & 81.45 & 15.06 & 5.41 \\
10 & 69.27 & 16.78 & 4.73 \\
\hline
\end{tabular}

Table 6. Effect of grinding time on the $M(\mathrm{~Pb})$.

\begin{tabular}{cccc}
\hline Grinding Time/min & $\boldsymbol{W ( P b ) / ( \% ) ^ { \mathbf { 2 } }}$ & $\boldsymbol{W}_{\mathbf{C}} / \mathbf{k w} \cdot \mathbf{h} \cdot \mathbf{t}^{-\mathbf{1}}$ & $\mathbf{M ( P b )}$ \\
\hline 2 & 31.53 & 9.01 & 3.50 \\
4 & 60.32 & 13.51 & 4.46 \\
6 & 53.32 & 14.32 & 3.72 \\
8 & 77.31 & 15.06 & 5.13 \\
10 & 64.39 & 16.78 & 4.39 \\
\hline
\end{tabular}



Figure 1. Effect of grinding time on the $W(\mathrm{Sn})$. 

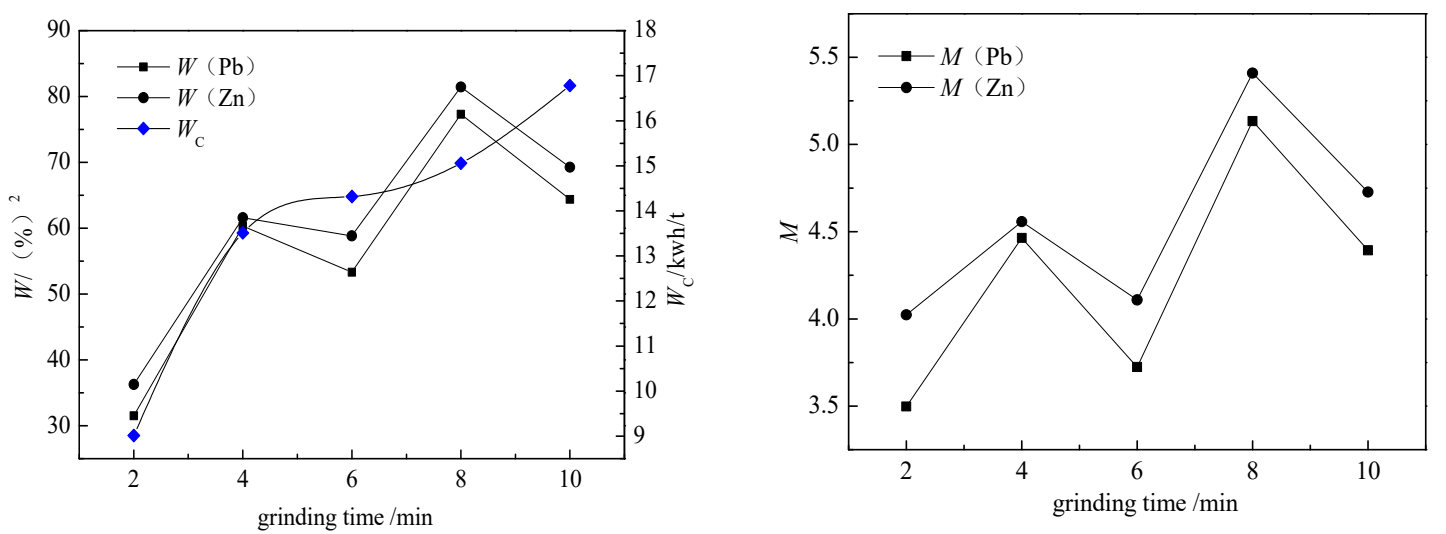

Figure 2. Effect of grinding time on the the $W(\mathrm{~Pb}), W(\mathrm{Zn}), M(\mathrm{~Pb})$ and $M(\mathrm{Zn})$.

Through the analysis of Tables 4-6 and Figures 1 and 2, the grinding optimization degree of the cassiterite and sulfide ore are the greatest when the grinding time is set at $4 \mathrm{~min}$ and $8 \mathrm{~min}$, respectively. This finding indicates that the cassiterite ore possesses good brittleness, low hardness and is easy to grind, while the sulfide ore has high hardness and is difficult to grind. Accordingly, the grinding optimization method can be proposed, that is, after the sequencing of tin grinding for 4 Min, another 4 min grinding is conducted to sort the sulfide ore. This process can alleviate the conflict of cassiterite overgrinding and sulfide ore undergrinding, and the grinding energy can also be utilized most efficiently.

\subsection{Effect of Grinding Concentration}

Grinding concentration refers to the percentage of minerals in the total pulp quality. The grinding concentration directly affects the grinding efficiency. The grinding test conditions were as follows. The grinding concentration was set at $35 \%, 45 \%, 55 \%, 65 \%, 75 \%$ and $85 \%$, the grinding time at $6 \mathrm{~min}$, the filling ratio at $32 \%$, the grinding particle size at $-1.7 \mathrm{~mm}$, and the rotational speed rate at $80 \%$. The effect of the grinding concentration on the grinding optimization degree of the cassiterite sulfide ore is shown in Tables 7-9 and Figures 3 and 4.

Table 7. Effect of grinding concentration on the $M(\mathrm{Sn})$.

\begin{tabular}{cccc}
\hline Concentration/\% & $\boldsymbol{W ( S n ) / ( \% ) ^ { \mathbf { 2 } }}$ & $\boldsymbol{W}_{\mathbf{C}} \mathbf{~} \mathbf{k w} \cdot \mathbf{h} \cdot \mathbf{t}^{\mathbf{- 1}}$ & $\mathbf{M}(\mathbf{S n})$ \\
\hline 35 & 40.97 & 13.68 & 2.99 \\
45 & 26.39 & 13.78 & 1.92 \\
55 & 52.81 & 14.14 & 3.73 \\
65 & 63.28 & 14.50 & 4.36 \\
75 & 17.85 & 14.42 & 1.24 \\
85 & 57.33 & 13.71 & 4.18 \\
\hline
\end{tabular}

Table 8. Effect of grinding concentration on the $M(\mathrm{Zn})$.

\begin{tabular}{cccc}
\hline Concentration/\% & $\boldsymbol{W ( Z n ) / ( \% ) ^ { \mathbf { 2 } }}$ & $\boldsymbol{W}_{\mathbf{C}} / \mathbf{k w} \cdot \mathbf{h} \cdot \mathbf{t}^{-\mathbf{1}}$ & $\mathbf{M ( Z n )}$ \\
\hline 35 & 51.61 & 13.68 & 3.77 \\
45 & 46.55 & 13.78 & 3.38 \\
55 & 60.53 & 14.14 & 4.28 \\
65 & 72.61 & 14.50 & 5.01 \\
75 & 58.74 & 14.42 & 4.07 \\
85 & 49.72 & 13.71 & 3.63 \\
\hline
\end{tabular}


Table 9. Effect of grinding concentration on the $M(\mathrm{~Pb})$.

\begin{tabular}{|c|c|c|c|}
\hline Concentration/\% & $W(\mathrm{~Pb}) /(\%)^{2}$ & $W_{C} / \mathrm{kw} \cdot \mathrm{h} \cdot \mathrm{t}^{-1}$ & $M(\mathrm{~Pb})$ \\
\hline 35 & 48.99 & 13.68 & 3.58 \\
\hline 45 & 42.87 & 13.78 & 3.11 \\
\hline 55 & 52.69 & 14.14 & 3.73 \\
\hline 65 & 64.14 & 14.50 & 4.42 \\
\hline 75 & 53.74 & 14.42 & 3.73 \\
\hline 85 & 56.40 & 13.71 & 4.11 \\
\hline
\end{tabular}
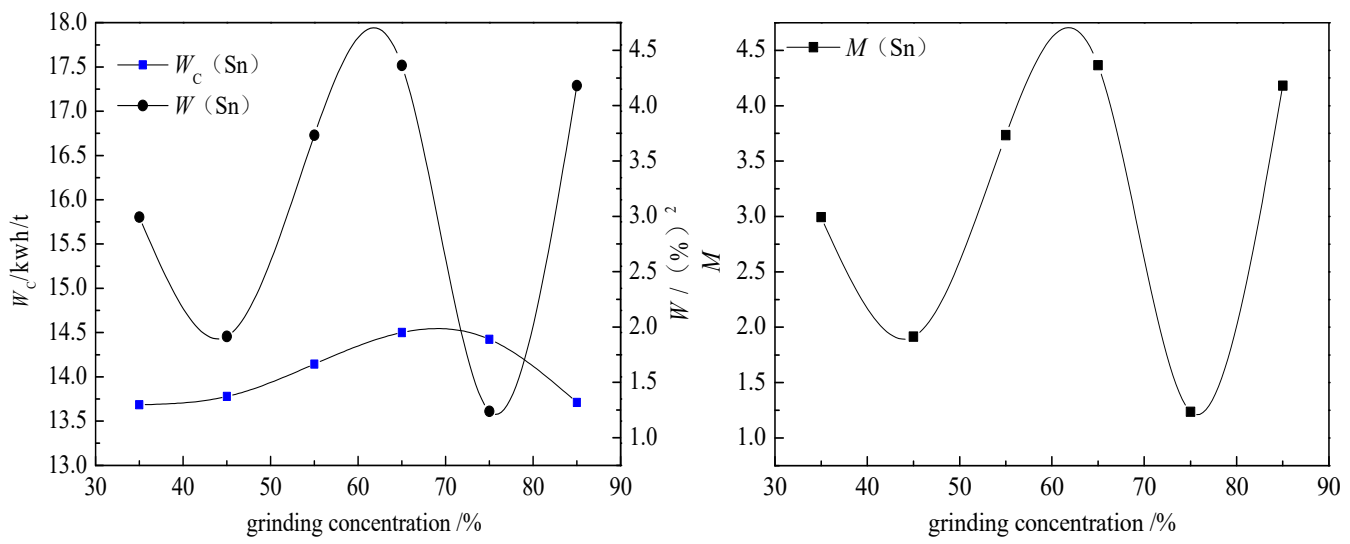

Figure 3. Effect of grinding concentration on the $W(\mathrm{Sn})$ and $M(\mathrm{Sn})$.



Figure 4. Effect of grinding concentration on the the $W(\mathrm{~Pb}), W(\mathrm{Zn}), M(\mathrm{~Pb})$ and $M(\mathrm{Zn})$.

If the grinding concentration is too high, the coarse and fine particles will not flow, and the steel ball will not play its role; if the grinding concentration is too low, the flow speed of the ore particles in the grinder will be high, and the chance of being impacted by the steel ball will be reduced. Therefore, suitable grinding concentration is very important for grinding efficiency. According to the analysis of Tables 7-9 and Figures 3 and 4, the grinding optimization degree of the cassiterite sulfide ore is the highest when the grinding concentration is $65 \%$.

\subsection{Effect of the Grinding Filling Ratio}

The grinding test conditions were as follows. The grinding filling ratio was set at $22 \%, 27 \%, 32 \%$, $37 \%$ and $42 \%$, the grinding time at $6 \mathrm{~min}$, the grinding concentration at $65 \%$, the filling ratio at $32 \%$, the grinding particle size at $-1.7 \mathrm{~mm}$ and the rotational speed rate at $80 \%$. The effect of the grinding filling ratio on the grinding optimization degree of the cassiterite sulfide ore is shown in Tables 10-12 and Figures 5 and 6. 
Table 10. Effect of the grinding filling ratio on the $M(S n)$.

\begin{tabular}{cccc}
\hline Filling Ratio/\% & $\boldsymbol{W ( S n ) /}$ & $\boldsymbol{W}_{\mathbf{C}} / \mathbf{k w} \cdot \mathbf{h} \cdot \mathbf{t}^{-\mathbf{1}}$ & $\boldsymbol{M ( S n )}$ \\
\hline 22 & 33.49 & 13.32 & 2.51 \\
27 & 52.06 & 13.47 & 3.86 \\
32 & 60.73 & 13.74 & 4.42 \\
37 & 63.84 & 13.78 & 4.63 \\
42 & 52.23 & 13.85 & 3.77 \\
\hline
\end{tabular}

Table 11. Effect of grinding filling ratio on the $M(\mathrm{Zn})$.

\begin{tabular}{cccc}
\hline Filling Ratio/\% & $W(\mathbf{Z n}) /(\mathbf{\%})^{\mathbf{2}}$ & $\boldsymbol{W}_{\mathbf{C}} \mathbf{~} \mathbf{k w} \cdot \mathbf{h} \cdot \mathbf{t}^{\mathbf{- 1}}$ & $\mathbf{M ( Z n )}$ \\
\hline 22 & 48.80 & 13.32 & 3.66 \\
27 & 50.25 & 13.47 & 3.73 \\
32 & 56.34 & 13.74 & 4.10 \\
37 & 68.74 & 13.78 & 4.99 \\
42 & 64.22 & 13.85 & 4.64 \\
\hline
\end{tabular}

Table 12. Effect of grinding filling ratio on the $M(\mathrm{~Pb})$.

\begin{tabular}{cccc}
\hline Filling Ratio/\% & $\boldsymbol{W ( P b ) / ( \% ) ^ { \mathbf { 2 } }}$ & $\boldsymbol{W}_{\mathbf{C}} \mathbf{~} \mathbf{k w} \cdot \mathbf{h} \cdot \mathbf{t}^{-\mathbf{1}}$ & $\mathbf{M ( P b )}$ \\
\hline 22 & 46.64 & 13.32 & 3.50 \\
27 & 48.31 & 13.47 & 3.59 \\
32 & 60.27 & 13.74 & 4.39 \\
37 & 58.92 & 13.78 & 4.28 \\
42 & 59.33 & 13.85 & 4.28 \\
\hline
\end{tabular}

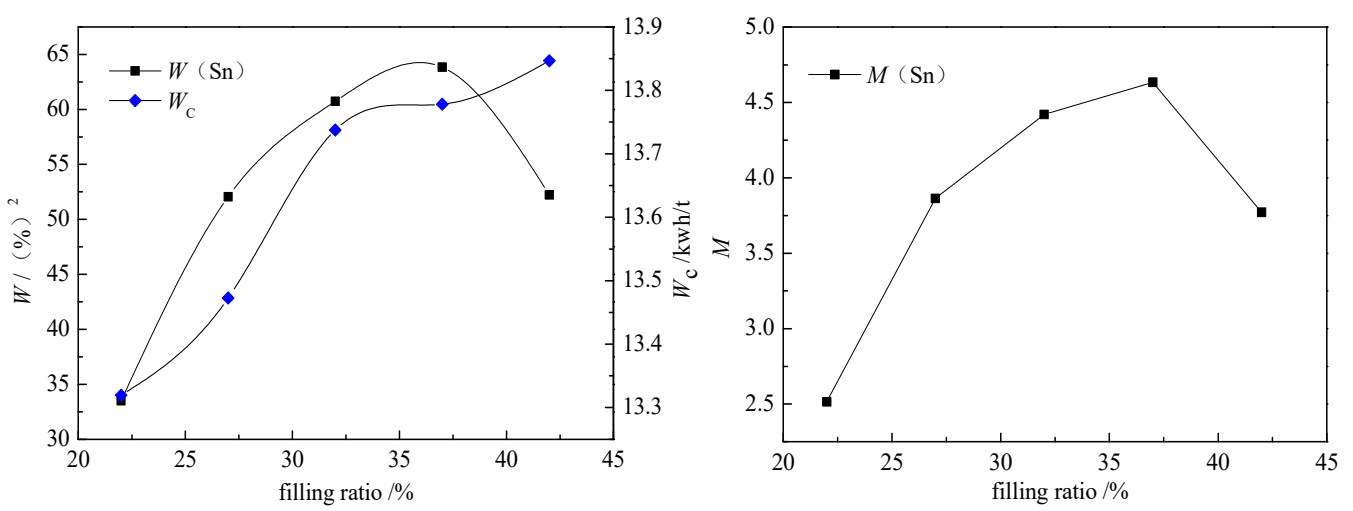

Figure 5. Effect of grinding filling ratio on the $W(\mathrm{Sn})$ and $M(\mathrm{Sn})$.

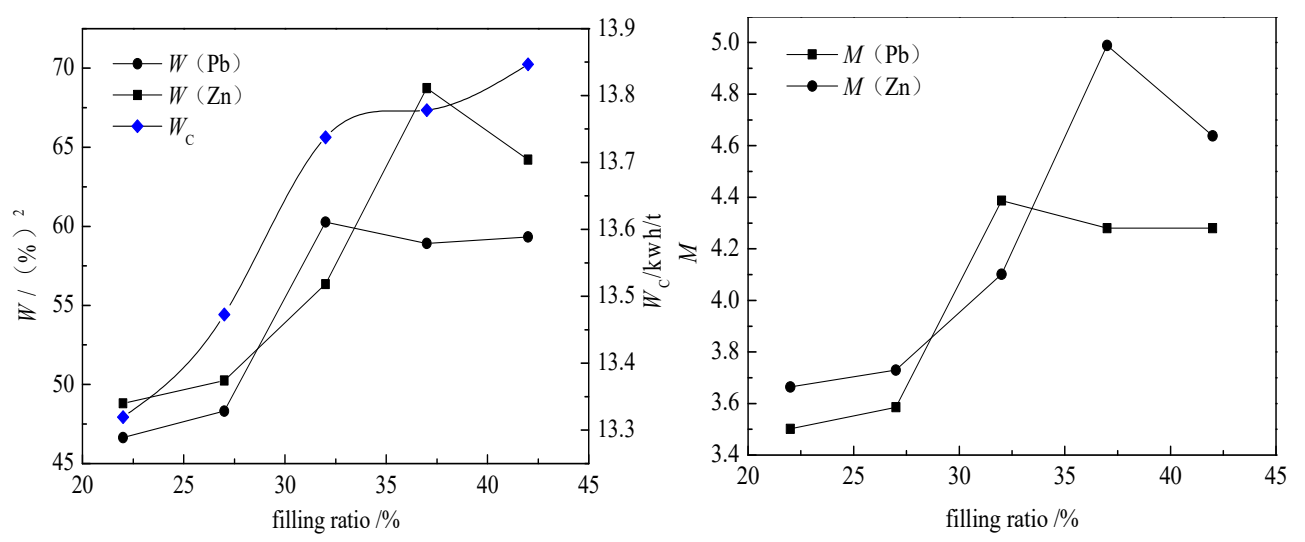

Figure 6. Effect of grinding filling ratio on the $W(\mathrm{~Pb}), W(\mathrm{Zn}), M(\mathrm{~Pb})$ and $M(\mathrm{Zn})$. 
When other factors remain unchanged, the grinding efficiency can be improved by properly increasing the filling ratio. If the filling ratio is too large, the probability of medium throwing motion is greatly reduced, and the liner wear is serious, which is not conducive to grinding. Through the analysis of Tables 10-12 and Figures 5 and 6, the grinding optimization degree is the highest when the grinding filling ratio is $37 \%$.

\section{Prediction and Verification of Optimization Conditions}

The prediction and verification of optimization conditions are based on a response surface method. The principle of this method is regression design, which involves finding the quantitative relationship between variables and independent variables. By analyzing the regression equation, the optimal process parameters were found, and the multivariable statistical method was solved by experimental analysis. According to the optimum grinding conditions, the prediction and verification experiments were carried out. The response surface method can be used to determine the optimum conditions for grinding time, grinding concentration, and filling ratio of the medium.

\subsection{Prediction Test of Grinding Parameters}

In this experiment, three parameters-grinding time, grinding concentration, and filling ratio, expressed by $X_{1}, X_{2}$ and $X_{3}$, respectively-were selected to analyze the response surface. The grinding optimization degree of $\mathrm{Sn}, \mathrm{Pb}$, and $\mathrm{Zn}$ was selected as the evaluation index of the response surface optimization in cassiterite polymetallic sulfide ore. These were called face values, with surface test values and surface predictive values included. Cassiterite mineral was represented by $\mathrm{Sn}$, and the sulfide minerals were represented by $\mathrm{Pb}$ and $\mathrm{Zn}$, and $M_{1}, M_{2}$ and $M_{3}$ were used to represent the predicted values of $\mathrm{Sn}, \mathrm{Pb}, \mathrm{Zn}$.

Based on the selected grinding parameters, 17 test combinations of three factors and three levels were designed from the Box-Behnken model. The test sequence was randomly generated by Design Expert 8.0.7 software, and the experimental value ranges of $\mathrm{Sn}, \mathrm{Pb}$ and $\mathrm{Zn}$ were 1.87-5.78, 3.50-4.93, and 3.86-5.77. The analysis shows that the correction coefficient and complex correlation coefficient of three metals in $\mathrm{Sn}, \mathrm{Pb}$ and $\mathrm{Zn}$ are the highest. These two models can be used as the regression equation between the surface test value and the grinding parameter. Through the Design Expert 8.0.7 software analysis and calculation, the fitting equations for $\mathrm{Sn}, \mathrm{Pb}$ and $\mathrm{Zn}$ between the surface test value and the grinding parameter are shown in Equations (6), (7) and (8), with $X_{1}, X_{2}$, and $X_{3}$ representing encoded values.

$$
\begin{aligned}
& M_{1}=5.76-0.32 X_{1}-0.58 X_{2}-0.21 X_{3}-0.43 X_{1} X_{2}-0.33 X_{1} X_{3}-0.76 X_{2} X_{3} \\
& -1.12 X_{1}^{2}-1.08 X_{2}^{2}-0.59 X_{3}^{2} \\
& M_{2}=4.89+0.03 X_{1}+(7.500 E-003) X_{2}+0.018 X_{3}-(7.500 E-003) X_{1} X_{2} \\
& -0.21 X_{1} X_{3}+0.083 X_{2} X_{3}-0.46 X_{1}^{2}-0.87 X_{2}^{2}-0.30 X_{3}^{2} \\
& M_{3}=5.71+0.016 X_{1}-(2.500 E-003) X_{2}+0.029 X_{3}-0.02 X_{1} X_{2}-0.18 X_{1} X_{3} \\
& -0.11 X_{2} X_{3}-0.73 X_{1}^{2}-1.01 X_{2}^{2}-0.48 X_{3}^{2}
\end{aligned}
$$

The surface test values, model predictive values and residuals of $\mathrm{Sn}, \mathrm{Pb}$ and $\mathrm{Zn}$ metal elements are shown in Figures 7 and 8, respectively. As shown in Figures 7 and 8, the experimental values and predicted values have a high fitting degree, indicating that the fitting of Equations (6), (7), and (8) can well describe the relationship between the surface test values and grinding parameters. 

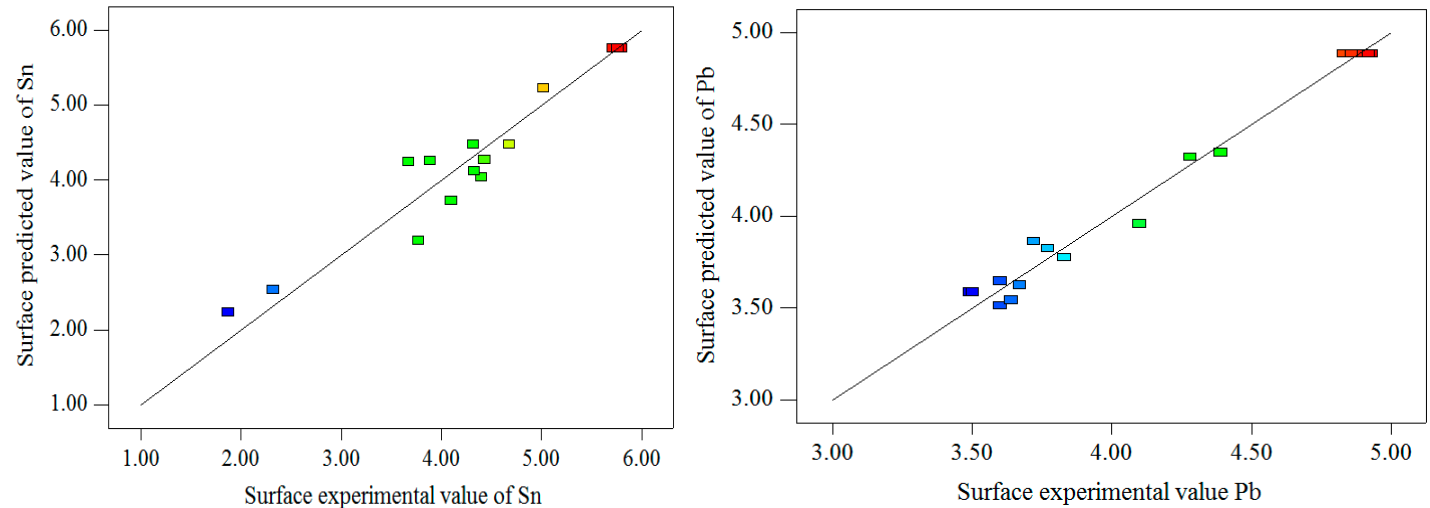

Figure 7. Comparison of the curved surface experimental and predicted values of the $\mathrm{Sn}$ and $\mathrm{Pb}$ grinding rate model.

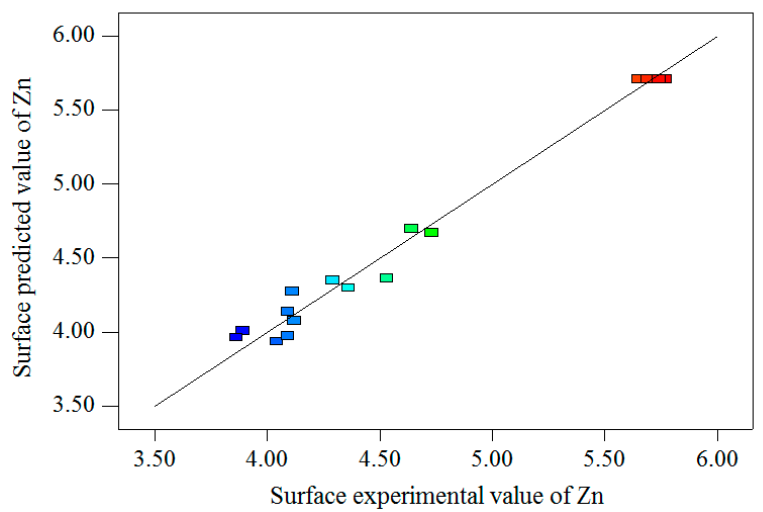

Figure 8. Comparison of the curved surface experimental and predicted values of the Zn grinding rate model.

Figures $9-17$ is a three-dimensional (3D) response surface map and a contour map for $\mathrm{Sn}, \mathrm{Pb}$, and $\mathrm{Zn}$ in response to a par value. The influence of two variables on the dependent variable can be more intuitively observed by the $3 \mathrm{D}$ response surface map. The contour map is a projection of the response surface graph.
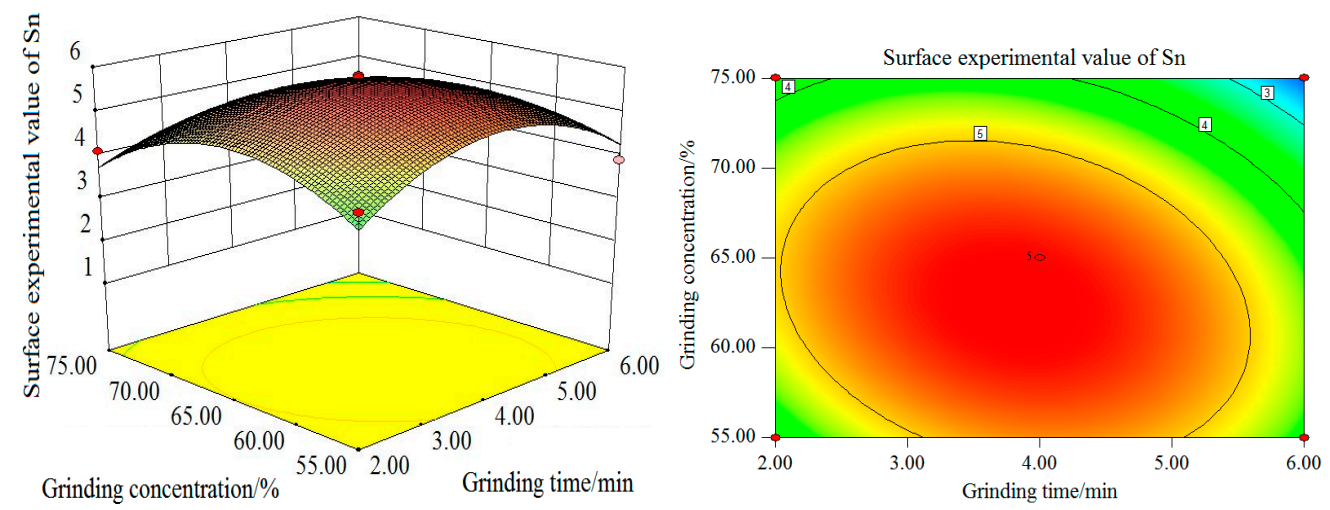

Figure 9. Sn curved surface experimental value and contour map under grinding concentration and grinding time action. 

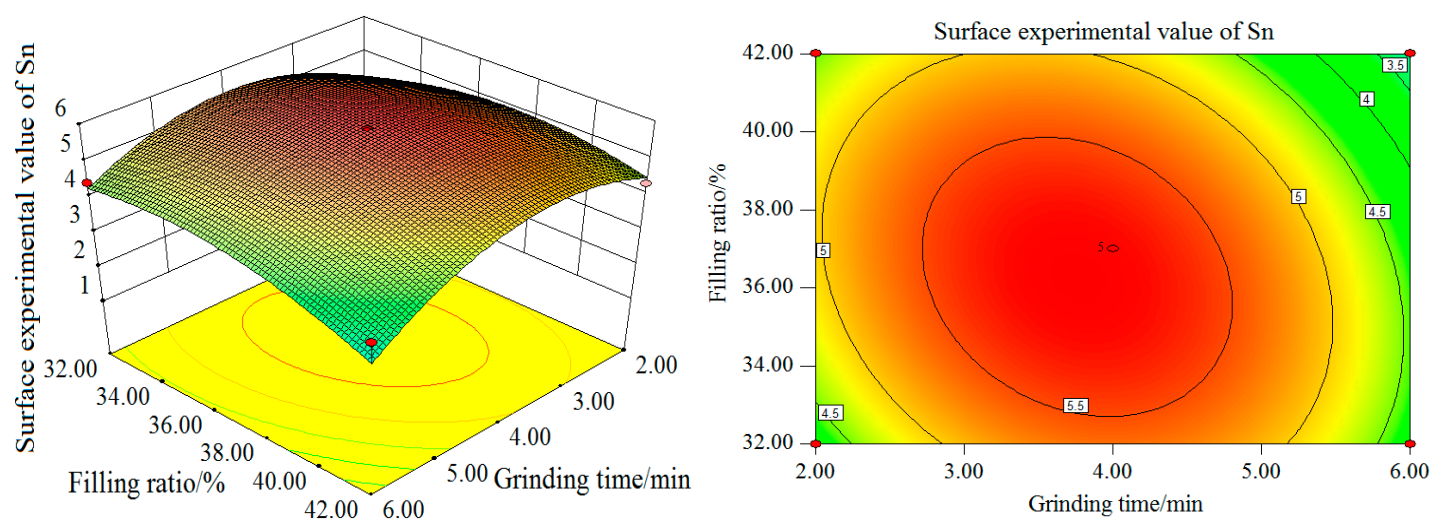

Figure 10. Sn curved surface experimental value and contour map under grinding time and grinding filling ratio action.


Figure 11. Sn curved surface experimental value and contour map under grinding concentration and grinding filling ratio action.
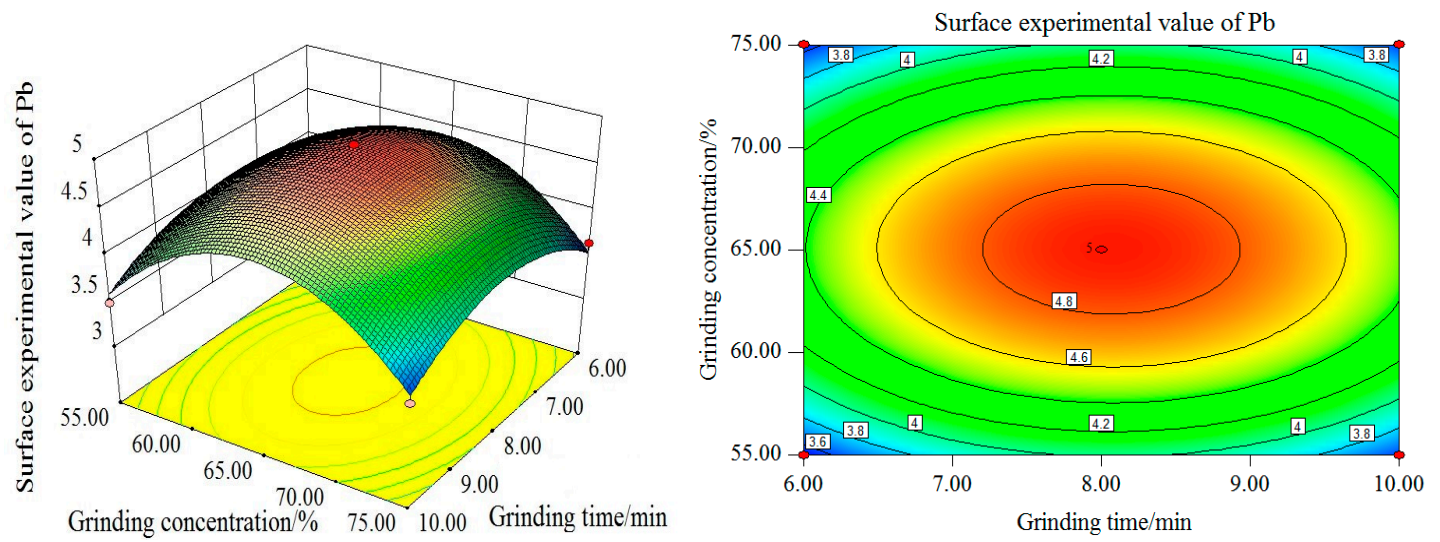

Figure 12. $\mathrm{Pb}$ curved surface experimental value and contour map under grinding concentration and grinding time action. 

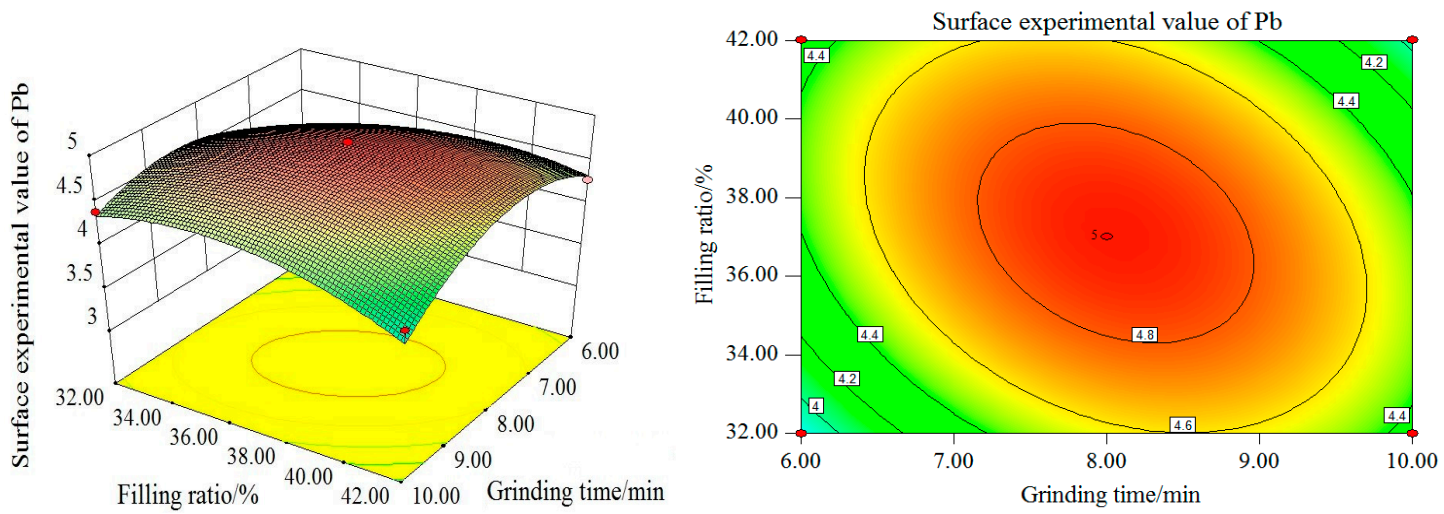

Figure 13. Pb curved surface experimental value and contour map under grinding time and grinding filling ratio action.
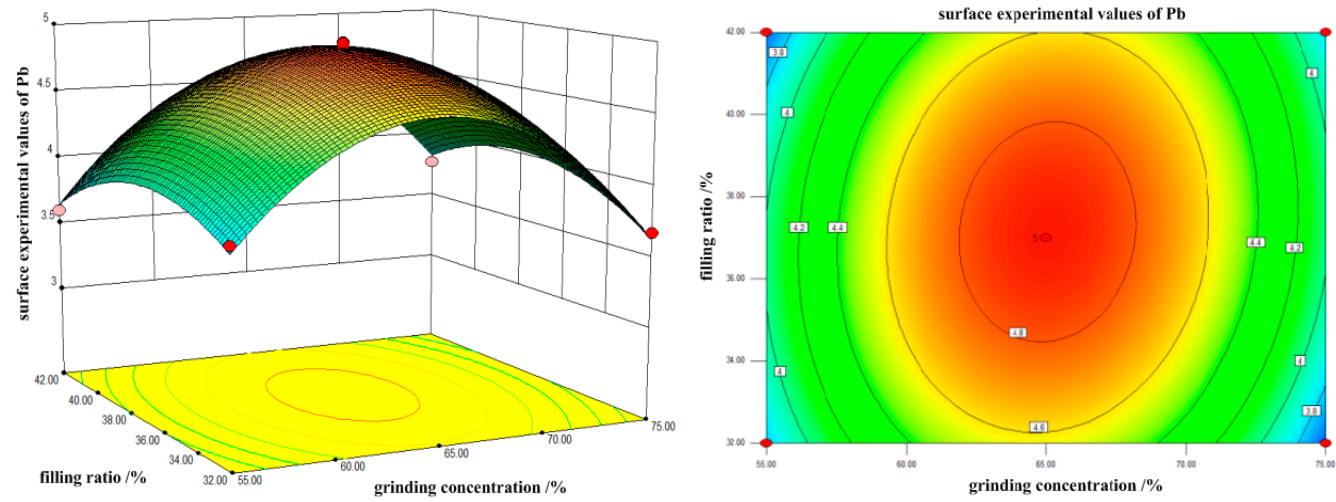

Figure 14. Pb curved surface experimental value and contour map under grinding concentration and grinding filling ratio action.
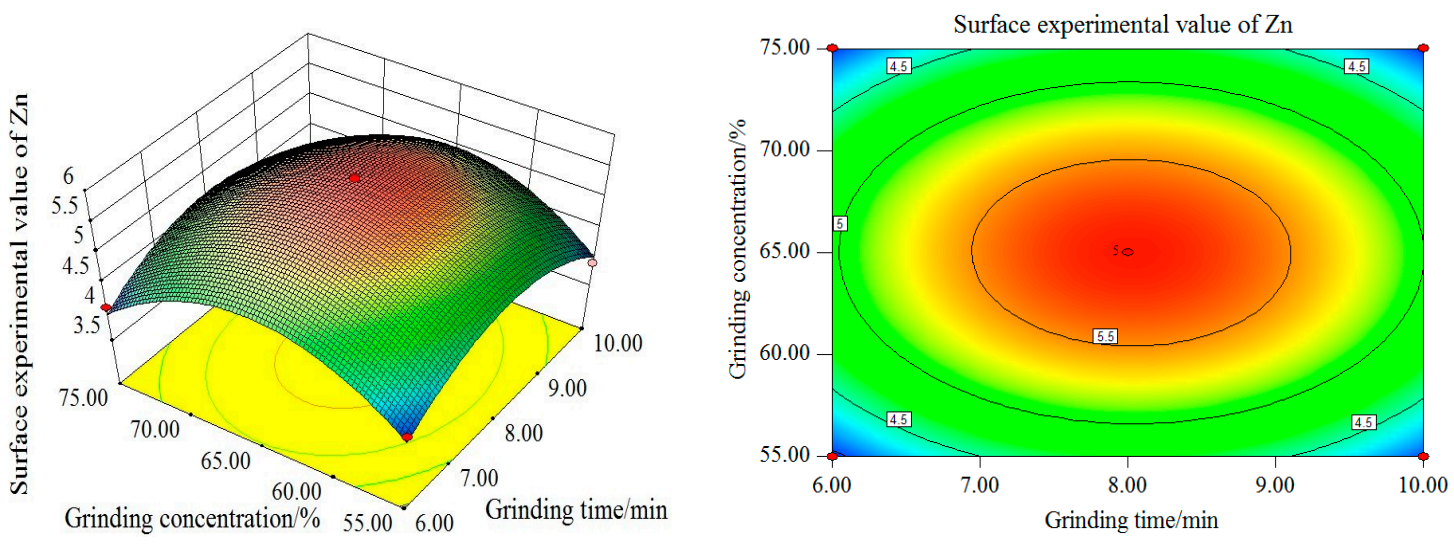

Figure 15. Zn curved surface experimental value and contour map under grinding concentration and grinding time action. 



Figure 16. Zn curved surface experimental value and contour map under grinding time and grinding filling ratio action.
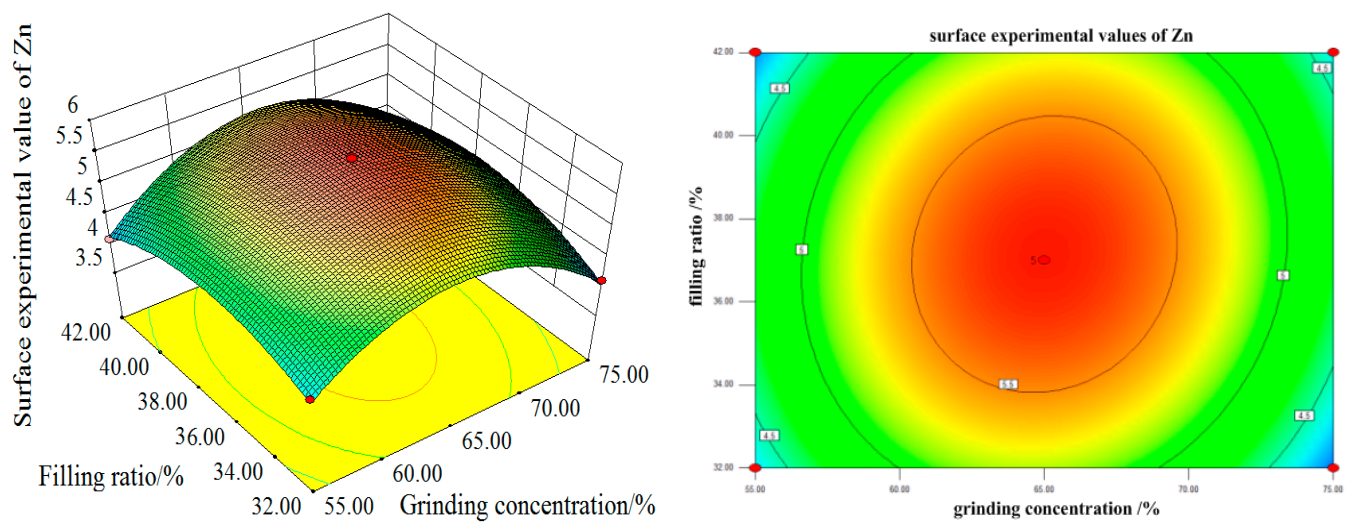

Figure 17. Zn curved surface experimental value and contour map under grinding concentration and grinding filling ratio action.

As shown in Figures 9-11, with the increase of grinding time and grinding concentration, the Sn surface test value firstly increases and then decreases, with the value reaching its maximum at grinding time of $4 \mathrm{~min}$ and grinding concentration of $65 \%$. In terms of the single factor, the grinding time and grinding concentration have a significant influence on the experimental value of the Sn curved surface. As can be seen from the contour map, the interaction between grinding time and grinding concentration is more significant. The influence curve between the filling ratio and grinding time on the experimental value of the Sn curved surface also shows a trend of increasing first and then decreasing. When the grinding time is $4 \mathrm{~min}$ and the filling ratio is about $37 \%$, the maximum $\mathrm{Sn}$ surface test value can be obtained. In terms of the single factor, the influence of grinding time on the experimental value of the $\mathrm{Sn}$ surface is greater than that of the filling ratio.

As can be seen from the contour map, the interaction between grinding time and the filling ratio is more significant. With the increase of the grinding concentration and filling ratio, the Sn surface test value increases first and then decreases. The maximum value is reached when the grinding concentration is $65 \%$ and the filling ratio about $37 \%$. In terms of the single factor, the influence of the grinding concentration on the experimental value of the $\mathrm{Sn}$ surface is greater than that of the filling ratio.

The contour map shows that the interaction between the grinding concentration and filling ratio is not significant. In summary, the order of influence degree on Sn surface test value from high to low is as follows: grinding time, grinding concentration, and filling ratio. The interaction between the grinding concentration and filling ratio is weak, while the interaction between the grinding time and grinding concentration and between the grinding time and filling ratio, is stronger. 
As shown in Figures 12-14, with the increase of grinding time and grinding concentration, the $\mathrm{Pb}$ surface test value firstly increases and then decreases, reaching its maximum when the grinding time is at $8 \mathrm{~min}$ and grinding concentration at $65 \%$. From the perspective of single factor, the influence of grinding time and grinding concentration on the experimental value of the $\mathrm{Pb}$ curved surface is remarkable. As can be seen from the contour map, the interaction between the grinding time and grinding concentration is more significant. The influence curve between the filling ratio and grinding time on the experimental value of $\mathrm{Pb}$ curved surface also increases first and then decreases. When the grinding time is $8 \mathrm{~min}$ and the filling ratio is about $37 \%$, the maximum $\mathrm{Pb}$ surface test value can be obtained.

In terms of the single factor, the experimental value of $\mathrm{Pb}$ curved surface is significantly affected by grinding time and filling ratio. As can be seen from the contour map, the interaction between the grinding time and filling ratio is more significant. With the increase in grinding concentration and filling ratio, the $\mathrm{Pb}$ surface test value increases first and then decreases. The maximum value is reached when the grinding concentration is $65 \%$ and the filling ratio is about $37 \%$. From the single factor, the filling ratio and grinding concentration have a significant influence on the experimental value of the $\mathrm{Pb}$ curved surface.

The contour map illustrates that the interaction between the grinding concentration and the filling ratio is not significant. In conclusion, the order of the influence degree on the Sn surface test value from high to low is as follows: grinding concentration, grinding time and filling ratio. The interaction between grinding concentration and filling ratio is weak, while the interaction between the grinding time and grinding concentration and between the grinding time and filling ratio, is stronger.

As shown in Figures 15-17, with the increase of grinding time and grinding concentration, the $\mathrm{Zn}$ surface test value firstly increases and then decreases, reaching its maximum at $8 \mathrm{~min}$ of grinding time and $65 \%$ of grinding concentration. From the single factor, the influence of grinding time and grinding concentration on the experimental value of the $\mathrm{Zn}$ curved surface is remarkable. As can be seen from the contour map, the interaction between the grinding time and the grinding concentration is more significant. The influence curve between the filling ratio and grinding time on the experimental value of the $\mathrm{Zn}$ curved surface also increases first and then decreases. When the grinding time is $8 \mathrm{~min}$ and the filling ratio is about $37 \%$, the maximum $\mathrm{Zn}$ surface test value can be obtained. From the single factor, the influence of grinding concentration on the experimental value of the $\mathrm{Zn}$ surface is more significant than that of the filling ratio.

It can be seen from the contour map that the interaction between the grinding time and filling ratio is not significant. With the increase in the grinding concentration and filling ratio, the $\mathrm{Zn}$ surface test value increases first and then decreases. The maximum value is reached when the grinding concentration is $65 \%$ and the filling ratio is about $37 \%$. From the single factor, the influence of grinding concentration on the experimental value of the $\mathrm{Zn}$ surface is more significant than that of the filling ratio.

The contour map illustrates that the interaction between the grinding concentration and the filling ratio is not significant. In summary, the order of the influence degree on the $\mathrm{Zn}$ surface test value from high to low is as follows: the grinding concentration, grinding time, and filling ratio. The interaction between the grinding concentration and grinding time is strong, the interaction between the grinding concentration and filling ratio is weak, and the interaction between the grinding time and filling ratio is weak.

\subsection{Grinding Verification Test}

The Sn surface design model can be obtained by accurately solving the model. The optimal theoretical parameters were a grinding time of $3.81 \mathrm{~min}$, grinding concentration of $62.42 \%$, and filling ratio of $37.07 \%$. Therefore, the predicted value of the Sn surface was 5.847. The optimal theoretical parameters of $\mathrm{Pb}$ and $\mathrm{Zn}$ surface design models were a grinding time of $8.03 \mathrm{~min}$, grinding concentration of $65.03 \%$, and filling ratio of $37.13 \%$. Accordingly, the prediction values of the $\mathrm{Pb}$ and $\mathrm{Zn}$ surface tests were 4.887 and 5.712, respectively. To verify the reliability and validity of the three equation models, A and B tests were carried out respectively on the prediction conditions and results. The results are shown in Tables 13 and 14. 
Table 13. Verification test results.

\begin{tabular}{|c|c|c|c|c|}
\hline Conditions and Results & Grinding Time/min & Grinding Concentration/\% & Filling Ratio/\% & $M(\mathrm{Sn})$ \\
\hline Prediction of optimal conditions and results & 3.81 & 62.42 & 37.07 & 5.847 \\
\hline A test conditions and results & 3.80 & 63.00 & 37.00 & 5.833 \\
\hline B test conditions and results & 3.80 & 63.00 & 37.00 & 5.854 \\
\hline \multirow{2}{*}{\multicolumn{4}{|c|}{$\begin{array}{l}\text { A error between experimental and predicted values } \\
\text { B error between experimental and predicted values }\end{array}$}} & $0.24 \%$ \\
\hline & & & & $-0.12 \%$ \\
\hline
\end{tabular}

Table 14. Verification test results.

\begin{tabular}{|c|c|c|c|c|c|}
\hline Conditions and Results & Grinding Time/min & Grinding Concentration/\% & Filling Ratio/\% & $M(\mathrm{~Pb})$ & $M(\mathrm{Zn})$ \\
\hline Prediction of optimal conditions and results & 8.03 & 65.03 & 37.13 & 4.887 & 5.712 \\
\hline A test conditions and results & 8.00 & 65.00 & 37.00 & 4.793 & 5.688 \\
\hline $\mathrm{B}$ test conditions and results & 8.00 & 65.00 & 37.00 & 4.910 & 5.783 \\
\hline \multirow{2}{*}{\multicolumn{4}{|c|}{$\begin{array}{l}\text { A error between experimental and predicted values } \\
\text { B error between experimental and predicted values }\end{array}$}} & $1.92 \%$ & $0.42 \%$ \\
\hline & & & & $-0.47 \%$ & $-1.24 \%$ \\
\hline
\end{tabular}

Through two verification tests, the conclusion can be reached that the predicted results were close to the experimental results, and the errors were within the range of $\pm 2 \%$. This finding shows that the model has strong reliability and validity. Therefore, on the premise of meeting the minimum energy consumption and the highest qualified particle size index, the grinding optimization condition of the cassiterite polymetallic sulfide ore can be obtained. Thus, $\mathrm{Sn}$, as the representative of cassiterite, achieves optimum grinding conditions with a grinding time of $3.8 \mathrm{~min}$, a grinding concentration of $63 \%$, and a filling ratio of $37 \%$. Polymetallic sulphide ore, represented by $\mathrm{Pb}$ and $\mathrm{Sn}$, achieves the optimum grinding conditions with a grinding time of $8 \mathrm{~min}$, a grinding concentration of $65 \%$ and a filling ratio of $37 \%$.

\section{Conclusions}

In this paper, a grinding optimization characterization method was proposed to characterize the grinding properties of the required particle size. It is referred to as the unit energy consumption of metal grade accumulation method.

Based on the experimental evaluation, the grinding time for reaching the highest grinding optimization degree of the cassiterite and sulfide ore was $4 \mathrm{~min}$ and $8 \mathrm{~min}$, respectively, indicating that the cassiterite ore is brittle and easy to grind with low hardness, while the sulfide ore is difficult to grind with high hardness. Accordingly, the grinding optimization method can be proposed on the theory of cassiterite polymetallic sulfide ore, i.e., sorting tin after 4 Min of grinding, followed by another 4-min grinding to sort the sulfide ore. This process can alleviate the conflict of cassiterite overgrinding and sulfide ore undergrinding, and ensure the grinding energy is most efficiently utilized. The optimum grinding concentration and filling ratio are $65 \%$ and $37 \%$, respectively.

Furthermore, the surface prediction results were close to the experimental results, and the errors were within the range of $\pm 2 \%$, indicating that the model has a strong reliability and validity. The effects of different grinding parameters on the surface test values of various elements including $\mathrm{Sn}, \mathrm{Pb}$ and $\mathrm{Zn}$, are different, and the interactions between different grinding parameters are also different.

Author Contributions: Conceptualization, J.Y. and S.M.; methodology, J.Y.; software, W.Z.; validation, Z.S., J.Y. and W.Z.; formal analysis, W.Z.; investigation, J.Y.; resources, S.M.; data curation, Z.S.; writing-original draft preparation, W.Z.; writing—review and editing, J.Y.; visualization, J.Y.; supervision, J.Y.; project administration, S.M.; funding acquisition, S.M.

Funding: The authors gratefully acknowledge the financial support for this study from the Natural Science Foundation of China (No. 51874105, No.51264001), Guangxi Natural Science Foundation (No. 2018GXNSFAA281204) and the 973 Program of China (No. 2014CB460606).

Conflicts of Interest: The authors declare no conflict of interest. 


\section{References}

1. Xu, T.L. Study on Cassiterite Polymetallic Sulfide Ore Selective Grinding Behavior; Guangxi University: Nanning, China, 2014. (In Chinese)

2. Liu, J. Experimental Study on Grinding Materials of a New Medium with Two Spheres in CheHe Concentrator; Guangxi University: Nanning, China, 2013. (In Chinese)

3. Qiu, G.Z.; Hu, Y.H.; Wang, D.Z. Interaction between Particles and Fine Flotation; Central South University of Technology Press: Changsha, China, 1993. (In Chinese)

4. Qin, W.Q.; Wang, P.P.; Ren, L.Y.; Wei, Q.; Peng, Z.B.; Gu, Y.L. Effect of matching relationship between particles and bubbles on the flotation of fine cassiterite. J. China Univ. Min. Technol. 2012, 41, 420.

5. Qin, W.Q.; Ren, L.Y.; Wang, P.P.; Yang, C.R.; Zhang, Y.S. Electro-flotation and collision-attachment mechanism of fine cassiterite. Trans. Nonferrous Met. Soc. China 2012, 22, 917. [CrossRef]

6. Sreenivas, T.; Padmanabhan, N.P.H. Surface chemistry and flotation of cassiterite with alkyl hydroxamates. Colloids Surf. 2001, 205, 47. [CrossRef]

7. Qin, W.Q.; Xu, Y.B.; Liu, H.; Ren, L.Y.; Yang, C.R. Flotation and surface behavior of cassiterite with salicylhydroxamic acid. Ind. Eng. Chem. Res. 2011, 50, 10778. [CrossRef]

8. Wu, X.Q.; Zhu, J.G. Selective flotation of cassiterite with benzohydroxamic acid. Min. Eng. 2006, $19,1410$. [CrossRef]

9. Bazin, C.; Obiang, P. Should the slurry density in a grinding mill be adjusted as a function of grinding media size. Min. Eng. 2007, 20, 810. [CrossRef]

10. Schmidt, J.; Plata, M.; Troger, S.; Peukert, W. Production of polymer particles below $5 \mu \mathrm{m}$ by wet grinding. Powder Technol. 2012, 228, 84-88. [CrossRef]

11. Matijasic, G.; Kurajica, S. Grinding kinetics of amorphous powder obtained by sol-gel process. Powder Technol. 2010, 197, 165. [CrossRef]

12. Fuerstenau, D.W.; Phatak, P.B.; Kapur, P.C.; Abouzeid, A.Z. Simulation of the grinding of coarse/fine (heterogeneous) systems in a ball mill. Int. J. Min. Process. 2011, 99, 32. [CrossRef]

13. Powell, M.S.; Weerasekara, N.S.; Cole, S.; LaRoche, R.D.; Favier, J. DEM modelling of linear evolution and its influence on grinding rate in ball mills. Min. Eng. 2011, 24, 341. [CrossRef]

14. Duan, X.X. Crushing and Grinding; Metallurgical Industry Press: Beijing, China, 2006. (In Chinese) 